\title{
KIT NM_000222.2:C.2492T>C
}

National Cancer Institute

\section{Source}

National Cancer Institute. KIT NM 000222.2:C.2492T>C. NCI Thesaurus. Code C155714.

A nucleotide substitution at position 2492 of the coding sequence of the KIT gene where thymine has been mutated to cytosine. 